\title{
EPIDURAL ANAESTHESIA-STILL A CINDERELLA?
}

\author{
Lieutenant Colonel D. I. MACNAIR, M.B., F.F.A.R.C.S., R.A.M.C. \\ Military Hospital, Catterick.
}

\begin{abstract}
SUMMARY: Recently Bevan and Austin (1970) analysed in this Journal 100 epidural anaesthetics with particular emphasis on the use of the technique for post-operative analgesia. The present article reviews 100 lumbar epidural anaesthetics performed by the writer in an eight month period in this hospital and reiterates the plea of Bevan and Austin for a more widespread consideration of the technique in military hospitals.
\end{abstract}

\section{Method}

Approach to the epidural spade was made with the patient in the left lateral position, awake but premedicated. Skin and supra-spinous ligament were infiltrated with 1 per cent lignocaine, a Size introducer was used to penetrate the skin and supra-spinous ligament and a Tuohy needle inserted. The epidural space was identified by the loss of resistance method using air as vehicle. An epidural catheter was passed and directed cephelad for $2-3 \mathrm{~cm}$. The needle was removed and the catheter strapped to a shoulder. The patient then moved into the supine position and a test dose of $40 \mathrm{mg}$ of 2 per cent lignocaine was injected. A vein was cannulated and basal readings of blood pressure and pulse rate were taken. The patient was then asked whether there were pins and needles in the legs and was asked to move the toes. After a negative response the definitive injection of analgesic was made and the trolley tilted as indicated. In general no tilt was applied to patients for limb surgery, 5-10 . Trendelenberg to those for lower and $10-15^{\circ}$ to those for upper abdominal surgery. When a thoracic epidural was performed the patient was tilted into $15^{\circ}$ of reverse Trendelenberg. Pulse rate and blood pressure were recorded at five minute intervals until the end of the surgical procedure. The level of analgesia was determined with a pin just prior to induction of general anaesthesia. The catheter was left in situ at the end of operation and further injections, usually of $20 \mathrm{ml}$ of 0.25 per cent bupivacaine, were made as indicated. The catheter was removed after 48 hours, or earlier if it had not been used for 12 hours. Like Bevan and Austin the writer has trained the nursing staff of Recovery ward to give the post-operative "top-up" injections and has left the timing of injections to their discretion.

\section{General Information}

Table I gives general information about the series. There was a slight preponderance of females and a tendency for them to be a few years older than the men, which is explained by the fact that many of the gynaecological patients were unconnected with the Services. There were four failures. Two were obese, a third was very agitated and in the fourth case the writer allowed himself to feel that he was in a hurry, for which he has only himself to blame. In retrospect the agitated patient should have been given a conventional anaesthetic.

\section{Technical information}

Table II provides some technical information. The premedicants used indicate the author's personal preferences. The level of approach to the epidural space must be read as approximate since few anaesthetists would claim to be certain exactly which space 
Table I

General information

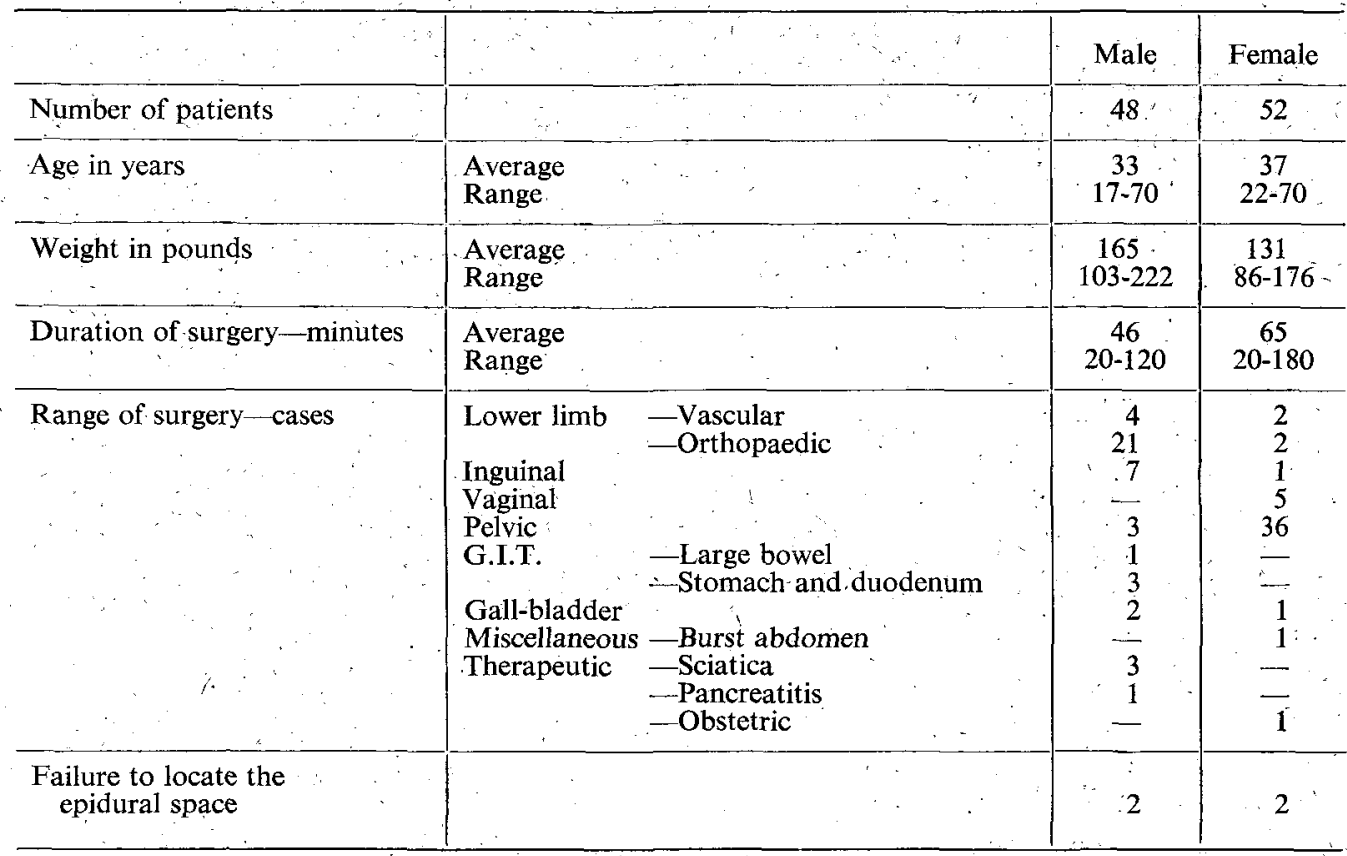

Table II :

Technical information

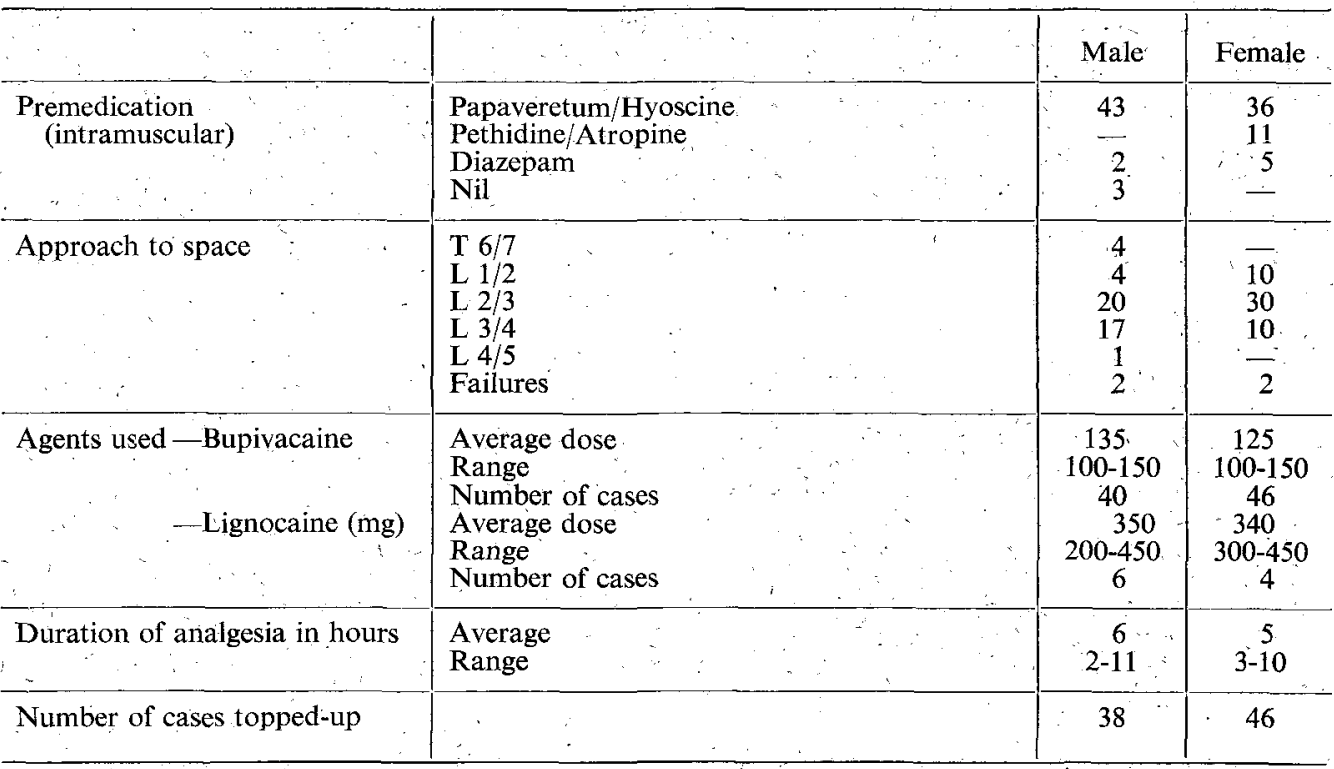

they were entering. When bupivacaine was used it was in 0.5 per cent strength and lignocaine was in 2 per cent strength. Although both solutions contained adrenaline 
they were autoclaved before use and adrenaline is not heat-stable. The duration of analgesia was taken as the time between the original injection and the first top-up injection:

\section{Anaesthetic information}

Table III

Anaesthetic information

\begin{tabular}{|c|c|c|c|}
\hline & $\because$ & Male & Female \\
\hline $\begin{array}{l}\text { Induction of general } \\
\text { anaesthesia } \\
\qquad\end{array}$ & 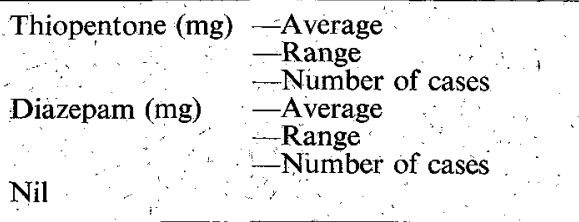 & $\begin{array}{c}400 \\
200-500 \\
39 \\
25 \\
20-30 \\
2 \\
5\end{array}$ & $\begin{array}{c}300 \\
200-350 \\
37 \\
20 \\
15-25 \\
11 \\
2\end{array}$ \\
\hline $\begin{array}{l}\text { Maintenance of anaesthesia } \\
\text {. }\end{array}$ & $\begin{array}{l}\text { Thiopentone }(\mathrm{mg}) \text { - Average } \\
\text {-Range } \\
\text { - Number of cases } \\
\text { Nitrous oxide alo } \\
\text { Nitrous oxide and halothane } \\
\text { Nil } \\
\text { Conventional methods after failed epidural }\end{array}$ & $\begin{array}{c}310 \\
100-850 \\
18 \\
1 \\
4 \\
18 \\
2\end{array}$ & $\begin{array}{l}280 \\
200-450 \\
27 \\
\frac{1}{1} \\
20 \\
2\end{array}$ \\
\hline
\end{tabular}

Table IHI gives general anaesthetic information. One patient, an S.R.N., elected to remain awake during operation but all other patients, given a choice, preferred to be asleep. That, of course, excludes the patients given a therepeutic epidural and the obstetric case. The fact that more female patients required supplemental thiopentone is probably explained by the longer average duration of their operations. The' patient given nitrous oxide required this to suppress retching during cholecystectomy. The female patient given nitrous oxide and halothane coughed persistently during hysterectomy and three of the men given the same sequence were given it to 'cover the vagotomy phase of vagotomy and pyloroplasty. The fourth man was inadequately analgesic at the groin during a Trendelenberg procedure for varicose veins but was analgesic postoperatively. Obviously inadequate time had been allowed for the epidural to take.

\section{Relationship of blood pressure to levels of approach and of analgesia}

Table IV interconnects the level of approach, the level of analgesia and blood pressure. There was a general tendency for the blood pressure to be lower when the level of approach was higher, and the time taken to reach that pressure to be longer. The level of analgesia obtained was similarly, related to the level of approach but not to a notable extent.

\section{Complications}

Table V lists the complications. There was no connection between the time at which patients vomited and the waning of analgesia or with post-operative hypotension. There was one case of erythema and discomfort round an epidural catheter on the second post-operative day. The catheter was removed and the erythema had subsided by the following day. 
Table IV

Relationship of blood pressure to level of approach and of analgesia

\begin{tabular}{|c|c|c|c|c|c|c|}
\hline \multirow[t]{2}{*}{ v } & \multicolumn{6}{|c|}{ Final systolic B.P. $(\mathrm{mm} / \mathrm{Hg})$} \\
\hline & 70 & 80 & 90 & 100 & 110 & $\begin{array}{r}\text { over } \\
110\end{array}$ \\
\hline $\begin{array}{ll}\text { Level of approach (number of cases) } & \mathrm{L} 1 / 2 \\
\mathrm{~L} 2 / 3 & \\
\mathrm{~L} 3 / 4 \\
\mathrm{~L} 4 / 5\end{array}$ & $\begin{array}{r}2 \\
5 \\
1 \\
-\end{array}$ & $\begin{array}{r}5 \\
15 \\
3 \\
-\end{array}$ & $\begin{array}{r}5 \\
18 \\
5 \\
-\end{array}$ & $\begin{array}{r}2 \\
2 \\
4 \\
-\end{array}$ & $\begin{array}{r}\overline{8} \\
12 \\
-\end{array}$ & $\begin{array}{l}\overline{2} \\
2 \\
1\end{array}$ \\
\hline Time to reach final systolic B.P. (minutes) & 60 & 45 & 35 & 30 & 20 & 5 \\
\hline $\begin{array}{l}\text { Average level of analgesia } \\
\text { (thoracic dermatomes) }\end{array}$ & 6 & 6 & 7 & 8 & 8 & 8 \\
\hline
\end{tabular}

Table V

Complications

\begin{tabular}{l|l|r|r}
\hline & & Male & Female \\
\hline Nausea and/or vomiting & $\begin{array}{l}\text { The day of operation } \\
\text { The day after operation }\end{array}$ & 2 & 13 \\
\hline Backache & $\begin{array}{l}\text { The day after operation } \\
\text { Thereafter }\end{array}$ & 3 & 4 \\
\hline Infection & $\begin{array}{l}\text { Erythema } \\
\text { More severe } \\
\text { Neurological }\end{array}$ & $\begin{array}{l}\text { Temporary } \\
\text { Permanent }\end{array}$ & - \\
\hline
\end{tabular}

One patient had no complaints while in hospital but mentioned when seen a month post-operatively in G.O.P.D. that she had pins and needles across an ankle. She was found to have diminution of pain sense in the distribution of L5 on the right. When seen again a month later she had neither symptoms nor signs.

\section{Patient reaction}

Table VI

Patient reaction

\begin{tabular}{ll|r|r}
\hline & & Male & Female \\
\hline Patient acceptability (number of cases) & - Pleased & 43 & 48 \\
& $\begin{array}{l}\text { - Unsure } \\
\text {-Displeased }\end{array}$ & 1 & 2 \\
\hline Comparison with other techniques (number of cases) & $\begin{array}{l}\text { - Better } \\
\text { - Unsure } \\
\text { - Worse }\end{array}$ & $\frac{6}{1}$ & 3 \\
\hline
\end{tabular}

It is evident from Table VI that most patients regarded epidural anaesthesia as acceptable. The most frequent comment was of a clear head on recovery and this 
seemed to be of more importance at that time than freedom from pain. Two men were uncertain about the technique as they could not see what was being done and two women were dubious for reasons that they would not or could not state. One man actively disliked the procedure but his dislike extended to all aspects of his admission. Eleven patients could give a valid comparison with previous 'traditional anaesthetics for an identical or similar operation. All but two preferred the epidural anaesthetic. One of those could give no reason for her uncertainty and the man, who had a second menicectomy, was the same man whose dislike was total.

\section{Discussion}

The writer's technique is broadly similar to that of Bevan and Austin. In the present series all patients were awake during induction of epidural anaesthesia. In all cases an epidural catheter was passed before any solution was injected and this is in accordance with the view of Wylie and Churchill-Davidson (1966). The 'writer prefers always to use air to detect loss of resistance for the simple reason that if fluid were to appear, there could be no doubt of it's origin. Unlike Bevan and Austin, the writer prefers Tuohy to Crawley needles. Lund (1966), in his book devoted to all aspects of epidural anaesthesia, makes the point that it is important to match needles to the technique for which they are intended and, to a lesser extent, to the method of identifying the epidural space. Selwyn Crawford (1972), a great protagonist in this country of obstetric epidural analgesia, favours a Macintosh balloon as indicator and carries two needles, of which the Tuohy is one. Massey Dawkins (1969) in his account of 4000 personal epidural blocks records a dural tap incidence of 7.5 per cent using a syringe to demonstrate loss of resistance as compared with 0.4 per cent with his modification of Brook's indicator, and intermediate figures with other methods. The workaday anaesthetist is thus left with the thought that the pundits vary considerably in their advice, of which the best is probably that one should master one technique rather than dabble in many (Wylie and Churchill-Davidson, 1966).

The writer has preferred to use intermittent supplements of thiopentone to maintain anaesthesia and has only resorted to inhalation methods where there has been a definite shortfall in the effectiveness of analgesia, or where, as. in the case of the vagus nerve at vagotomy, a nerve has been known to be beyond the reach of the epidural agent. In the writer's experience, no surgeon had complained of inadequate muscle relaxation, whatever reservations they may have had in other respects.

After the appearance in anaesthetic journals of papers extolling the virtues of bupivacaine (Watt, Ross and Atkinson 1968 a and b) for epidural analgesia, it has become increasingly popular and is the writer's agent of choice. Only when the shorter. latent period of lignocaine seemed to be of importance was it preferred to bupivacaine. Postoperative 'top-ups' were regarded as part of the anaesthetic sequence and were performed in most cases. Of the men who did not require top-up, three had had a therapeutic epidural, two had had a prostatectomy and two varicose vein operations. The obstetric case did not require a top-up, nor did two women after varicose vein operations or the one who had had a repair of burst abdomen. Like Bevan and Austin, the writer feels that it is in the realm of post-operative analgesia that an epidural has most to offer to the routine case. 
The question of the optimal strength and volume of epidural solutions remains open. Bromage (1962) found that the number of dermatomes reached depended on the mass of solute, but Erdemir, Soper and Sweet (1965) concluded that a greater volume of a more dilute solution spread further than the reverse. In the present series the writer attempted in a number of patients to use $10 \mathrm{ml}$ of bupivacaine 0.5 per cent. For several this was not adequate but in all of them a subsequent injection of $20 \mathrm{ml}$ of 0.25 per cent bupivacaine was effective.

The reaction of the patient to epidural is clearly of great importance and, to borrow an aphorism from the business world, the best salesman is a satisfied customer.

The writer has found that if there is in the ward a patient who has had an epidural, potential candidates need little persuasion of the benefits of the technique. Ward staff also help in reassuring patients and this has seemed to be of particular value in female wards.

Surgeons vary between deep suspicion and embarrassing enthusiasm and since their relationship to patients is more central than is that of anaesthetists, surgeons must be convinced. Certain virtues should be obvious and the case of the man with chest infection which Bevan and Austin cite makes the point well. Contracted bowel, a "spinoff, of epidural anaesthesia, can simplify a surgeon's task and the reduction in blood loss which is a feature in pelvic and vaginal surgery makes an instant appeal to, gynaecologists. The Department of Physical Medicine of this hospital has felt that patients mobilise more rapidly after meniscectomy when they have had an epidural and it is hoped that a quantitative assessment of this impression will be made. Articles from Swerdlow and Sayle-Creer (1970) and Dilke, Barry and Grahame (1973) encouraged the writer to provide for the Department of Physical Medicine epidural methylprednisolone in three cases of lumbar nerve root compression. Although the size of the Anaesthetic Department precludes a comprehensive obstetric epidural service one patient with a low pain threshold received an epidural. It was difficult to decide whether the patient or the obstetrician was the more relieved.

\section{Acknowledgements}

The author would like to thank Lieutenant-Colonels R. C. Francis M.R.C.O.G., and N. H. Peters F.R.C.S., for their forbearance, Lieutenant-Colonel A. R. Robinson M.R.C.P., for his infectious enthusiasm and Capt. Margaret Hudson S.R.N., for her. expert supervision in the Recovery. Ward.

\section{REFERENCES}

Bevan, D. R. and Austin, T. R. (1970). J. roy. Army. med. Cps 116, 190.

Bromage, P. R. (1962). Brit. J. Anesth. 34, 161 .

CRAWford, J. S. (1972). Principles and Practice of Obstetric Anaesthesia. 3rd ed. Blackwell Scientific Publications. Oxford.

Dilke, T. F. W., Burry, H. C. and Grahame, R. (1973). Brit. mèd. J. ii, 635.

Erdemir, H. H., Soper, L.E. and Sweet, R. B. (1965). Anesth. Analg. Curr. Res. 44,400.

Lund, P. C. (1966). Peridural Analgesia and Anaesthesia. 1st. ed. Charles C. Thomas. 1llinois.

Massey Dawkins, C. J. (1969). Anaesthesia 24, 554.

SWERdow, M. and SAYLE-CREer, W. (1970). Anaesthesia 25, 341.

Watt, M. J., Ross, D. P. and Atkinson, R. S. (1968a). Anaesthesia 23, 2.

Watt, M. J., Rodd, D. P. and AtKinson, R. S. (1968b). Anaesthesia 23, 331.

WYlie, W. D. and ChurChill-Davidson; H. C. (1966). A Practice of Anaesthesia. 2nd ed. Lloyd-Luke (Medical Books) Ltd. London. 